\title{
PRACTICAL REALIZATIONS OF A GENERALIZED ADVERTISING CYBERNETIC MODEL
}

\author{
Serhii Ostrianyn ${ }^{1}$, Oleksandr Yakovenko ${ }^{2}$
}

\begin{abstract}
Nowadays, a big number of various math models of advertising exists, however all of them describe only specific effects of advertising influence, thus, considering most modern advertising campaign utilize multiple ad channels for different purposes and are highly integrated, systematic and complex in its structure, math modelling of such campaigns remains a challenge for practitioners. As for today, there is no such framework that would be flexible and effective enough in solving tasks of advertising campaigns management. Hence, a framework of generalized advertising modelling and illustrations of its practical realizations for particular real cases would be a valuable addition to the research of the topic as well as a useful manual for practitioners. An objective of the current article is to illustrate various cases of generalized advertising model realizations, explain framework and algorithm of building model's realizations for particular integrated marketing campaigns and show economic effects of proposed approach on an example of a real enterprise. Proposed framework is especially focused on modelling sequential and structured customer journeys and utilizing its systematic effects which become a modern standard of advertising activities among the enterprises. Article also includes considerations of modelling modern marketing tools such as WOMM and its integration into advertising campaigns utilizing more conventional tools which is illustrated for a first time in research literature on the topic. Proposed model supports taking into account indirect advertising tools which are not resulting in purchase directly, however, build awareness or move customers towards a purchase within a customer journey in any other way. Present research uses such methods as synthesis, generalization, case study and a real-field experiment. Results of this research can be useful for marketing practitioners as a guidance for building math models of bespoke advertising campaigns. Provided guide also shows how to turn built model into an optimization one and use it as a support for budgeting decision making process. Cases of practical application of proposed guide show improvement of profitability of advertising campaign ranging between $3.6 \%$ and $30 \%$ percent depending on market peculiarities.
\end{abstract}

Key words: marketing, advertising, math modeling, cybernetic model, word of mouth, generalization, customer journey.

JEL Classification: M37, C53

\section{Introduction}

Research in fields of psychology, mass communication and the theory of economic decision making defined and formalized strong links between sales and advertising and described different effects of advertising influence. In parallel, explosive growth of digital technologies and digitalization of all the parts of life related to market and consumptions took place. Modern information technologies have made possible gathering big data sets which describe consumers' behavior in conjunction with advertising impact. (Ostrianyn, Dynamic budgeting of an advertising campaign, 2017) All that prerequisites have enabled complex and integrated advertising campaigns which are no longer a simple set of various channels distributing the same advertising message, but a system of different advertising tools which can be fine-tuned towards the goal of making customers purchasing advertised goods and services. Customer behavior also became more complex and now it can only be influenced by precise advertising campaigns, rather than broad and plain ones. Moreover, markets move towards developing numerous niches with its specific audiences and customer journeys within which

\footnotetext{
Corresponding author:

${ }^{1}$ Oles Honchar Dnipro National University, Ukraine.

E-mail: serge.alexsson@gmail.com

ORCID: https://orcid.org/0000-0001-9012-9913

${ }^{2}$ Oles Honchar Dnipro National University, Ukraine.

E-mail: yakovenkoA@i.ua

ORCID: https://orcid.org/0000-0003-1315-6322
}

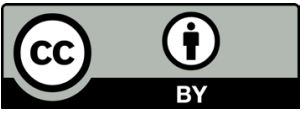

This is an Open Access article, distributed under the terms of the Creative Commons Attribution CC BY 4.0 
consumers learn about available offers, make purchase decisions and interact with the enterprise. Hence, it is impossible for enterprises to use available advertising models which describe only specific advertising effects separately. New advertising tools also keep being developed and not seldom there is a lack of modelling proposed for such tools. Considering all of that it appears to be relevant and needed to come up with such a framework which would allow advertising practitioners to build custom modelling realizations of campaigns utilizing new advertising tools as well as considering those tools as parts of a system. Present article explains main concepts of the generalized model, describes the process of assembling its practical realizations as a sequence of building a conceptual model of a campaign for the particular set of advertising tools and desired customer journey at first, descriptive and, consequently, optimization budgeting math model of a planned campaign. Article also features illustrations of suggested steps and provides economic results of real-field application of a model assembled according to the proposed guide.

\section{Literature review}

A little research done on topic of generalized advertising models is known to date. Most related works include those of reconsidering classic AIDA linear marketing model by adding more steps to it such as (Sukma Wijaya, 2012); developing a theoretical framework of social media advertising model as a part of Integrated Marketing Communication (Ahmed \& Mustafa Raziq, 2017); considering hybrid marketing mix within integrated marketing communications (Naumovska \& Blazeska, 2016); approaching multichannel, multi-audience communication (Key \& Czaplewski, 2017); proposing customer-integrated marketing communication (Finne \& Grönroos, 2017). However, all of those works are purely conceptual in their nature and there's little to no math modelling proposed on the topic of consideration. Thus, developing and proving such a model is of nowness and value to the frontier of marketing research.

\section{Generalized model framework}

\subsection{Conceptual model assembling}

Let's overview main concepts of the generalized model. The main element of the model is a stage which can represent a step of a supposed consumer decision making process, a touchpoint within a customer journey which is a place where an information interaction between enterprise and the customerhappens or a group of customers which is believed to be sensitive to particular messages and tending towards particular action. Practitioners should conduct an observation of its audience and split it up into several stages.
As a next step, model builders should consider how usually customers move between the stages, keeping in mind that linear movements in one direction are obsolete and reality proves to be more complex, hence analyzing customer data is handy for that task. Moves between the stages can be caused by natural factors such as changing customer needs, seasonality or any other factors and by intentional factors such as advertising or any other information passed by an enterprise to customers of the stage. Hence, a number of customers of particular stage may be described as a function with a number of customers from other stages in the previous period as an argument of that function. A function choice should rely on the nature of a transition between the stages and in case of uncertainty a black-box modelling with use of artificial neural networks can be applied. Once the structure of stages and links between them is defined, making a conceptual model of a campaign may be considered as done.

\subsection{Descriptive model assembling}

Next step of a framework is assembling of a descriptive math model. In general case, let $M_{i j t}$ be the number of consumers that move from stage $i$ to stage $j$ at the moment $t$. In general, this move is being defined by a formula:

$$
M_{i j t}=f\left(S_{i t}, g_{c t}\right) i \in I, c \in C
$$

$I$ - a number of stages defined for a particular model realization,

$C$ - a number of targeted advertising tools.

Hence, a number of consumers at the stage $i$ is being defined as following:

$$
S_{i t}=S_{i t-1}+\sum_{j=1}^{J} M_{j i t-1}-\sum_{j=1}^{J} M_{i j t-1}
$$

We will illustrate this step on an example of building a model for advertising campaign which utilizes both traditional advertising as well as word of mouth marketing. Before considering particular realization of generalized model, we will provide explanations of model capabilities of generalization and adjustment to distinctive peculiarities of an advertising campaign and behavior of consumers of different market categories within WOM process.

Global market penetration of social networks, which create far more social links, hence, peer to peer communication channels, streamlined strengthening and widening of "word of mouth" communication effects as a viable alternative to traditional advertising tools within advertising campaigns. An abbreviation of WOM (word of mouth) is commonly adopted in literature as well as its use for the benefit of the firm - WOMM (word of mouth marketing), hence we will utilize those abbreviations further. (Kozinets, de Valck, Wojnicki, \& Wilner, 2010) Let's use 
a concept of touchpoints (Ostrianyn \& Yakovenko, GENERALIZED MODEL OF THE ENTERPRISE MARKETING ACTIVITY MANAGEMENT, 2020) and define main groups of consumers within WOM context:

1. $S_{1}$ - consumers which do not consider purchasing decision hence are not sensitive to recommendations. It happens due to a couple of reasons: first, they are not conducting active information gathering and, second, they won't remember either positive or negative peer feedback as they are not interested in that information at the moment.

2. $S_{2}$ - consumers which are considering purchasing decision hence are sensitive to recommendations and feedbacks. It is commonly known that thanks to aggregators and social networks peer recommendations are easily accessible.

3. $S_{3}$ - consumers which have made a purchase and formed a positive impression of it and tend to leave positive feedbacks.

4. $S_{4}$ - consumers which are not satisfied with the purchase so that they will leave negative feedbacks and refuse others to make a purchase.

5. $S_{5}-$ as a certain time is needed to make an impression of a purchase it makes sense to define a separate group for consumers which have made a purchase and haven't come to particular conclusion yet.

Let the system be a closed one as for the companies that last less than a year, which is typical for an industry, demographic data and, consequently, the overall number of consumers at the market remains the same. This overall number can be distributed among a set of groups, let it be five based on aforementioned reasons. Under the influence of different factors consumers migrate among those five stages so that the number of consumers in each group changes as the time passes. Those migrations can be caused by the following reasons:

1. Natural effects such as losing an interest or a need in a purchase or a disappointment of a product category.
2. WOM effects caused by the fact that consumers of different groups do communicate with each other and this communication makes an impact on consumers' behavior.

3. Effects of targeted advertising.

In order to visualize capabilities of generalized model we will build a WOMM model based on it, which will utilize effects of feedbacks on consumers' behavior.

We will use a model proposed in ( $\mathrm{Li}$, et al., 2018) as a starting point but will make it a closed one based on assumption provided earlier. Let's consider its organic dynamic more thoroughly:

1. Under an influence of numerous uncontrolled factors (Ostrianyn \& Yakovenko, MODELING OF ADVERTISING ACTIVITY IN CONDITIONS OF UNCONTROLLED DEMAND FACTORS, 2020) and an advertising itself a certain number of consumers joins a group of those who plan a purchase.

2. Under an influence of positive recommendations (Yakovenko, 2017) sensitive consumers make a purchasing decision.

3. A positive impression is being formed which causes a desire to recommend.

4. A negative impression is being formed.

5. Due to the desire to make a repetitive purchase, a positively impressed consumer again becomes sensitive and makes a decision.

6. Positively impressed consumers leave a group of product target audience due to some reasons.

7. Unsatisfied consumers leave a market group due to some reasons.

8. Due to the desire to make a repetitive purchase, a consumer again becomes sensitive and makes a decision.

9. Consumers leave market group as the purchase is made and the need is met.

10. Under an influence of negative comments consumers leave a market group

All the links are shown on the diagram (see Figure 1).

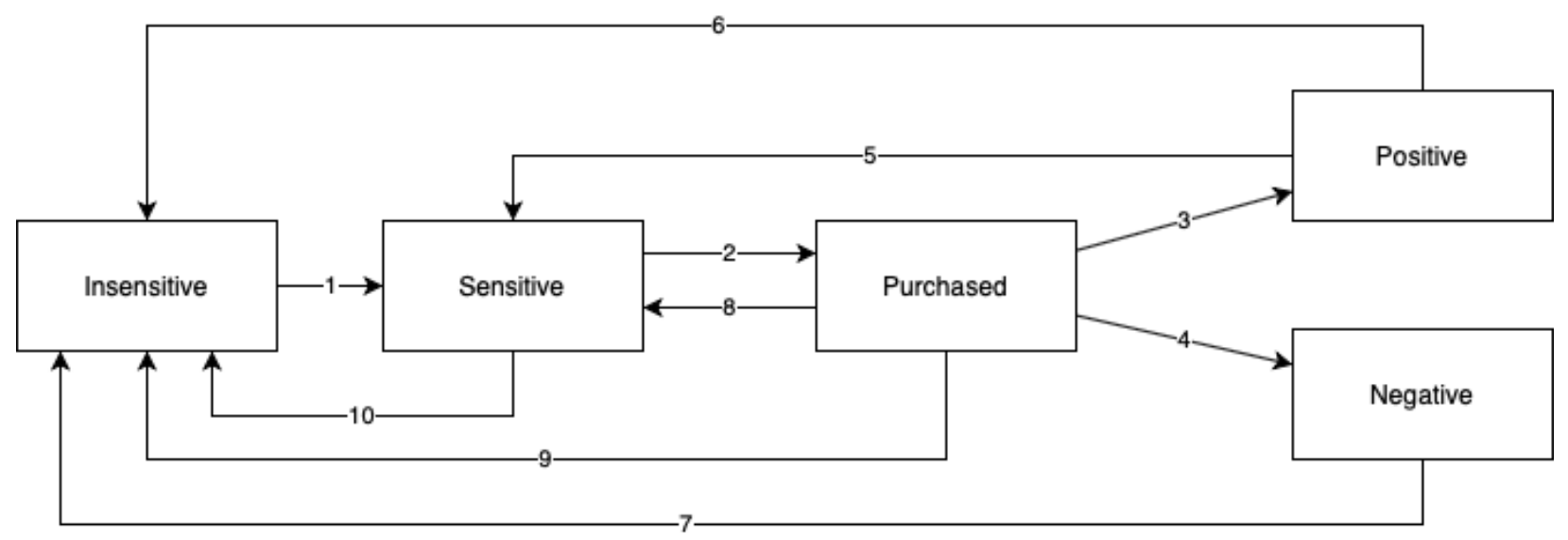

Figure 1. Improved conceptual scheme of WOMM 
Let's provide a concrete math definition of a proposed model. For convenience we will describe all defined moves $M_{i j t}$ in Table 1 . Rows represent stages $i$ while columns - stages $j$. Hence, there are formulas of all defined moves $M_{i j t}$ on the intersections of rows and columns. Dashes marks irrelevant moves such as consumers which haven't made a purchase forming a positive or negative attitude. Questions mark moves which require additional research and hypothetically can be meaningful. The main diagonal of a matrix is left blank as, naturally, if consumers do not move, then they remain on the particular stage.

Math model can be described as a set of equations:
Table 1

Definitions of move among stages

\begin{tabular}{|c|c|c|c|c|c|}
\hline & $S_{1}$ & $S_{2}$ & $S_{3}$ & $S_{4}$ & $S_{5}$ \\
\hline$S_{1}$ & & $\propto S_{1}$ & $?$ & - & - \\
\hline$S_{2}$ & $\beta_{N} S_{5}$ & & $\beta_{P} S_{4}$ & - & - \\
\hline$S_{3}$ & $\delta_{I} S_{3}$ & $\gamma_{I} S_{3}$ & & $\alpha_{P} S_{3}$ & $\alpha_{N} S_{3}$ \\
\hline$S_{4}$ & $\delta_{P} S_{4}$ & $\gamma_{P} S_{4}$ & $?$ & & - \\
\hline$S_{5}$ & $\delta_{N} S_{5}$ & $?$ & $?$ & - & \\
\hline
\end{tabular}

$$
\left\{\begin{array}{c}
S_{1}(t+1)=S_{1}(t)+\beta_{N} S_{5}(t) S_{2}(t)+\delta_{I} S_{3}(t)+\delta_{P} S_{4}(t)+\delta_{N} S_{5}(t)-\mu S_{1}(t) \\
S_{2}(t+1)=S_{2}(t)+\mu S_{1}(t)+\gamma_{I} S_{3}(t)+\gamma_{P} S_{4}(t)-\beta_{N} S_{5}(t)-\beta_{P} S_{4}(t) \\
S_{3}(t+1)=S_{3}(t)+\beta_{P} S_{4}(t) S_{2}(t)-\delta_{I} S_{3}(t)-\gamma_{I} S_{3}(t)-\alpha_{P} S_{3}(t)-\alpha_{N} S_{3}(t) \\
S_{4}(t+1)=S_{4}(t)+\alpha_{P} S_{3}(t)-\delta_{P} S_{4}(t)-\gamma_{P} S_{4}(t) \\
S_{5}(t+1)=S_{5}(t)+\alpha_{N} S_{3}(t)-\delta_{N} S_{5}(t)
\end{array}\right.
$$

$\delta_{I}, \delta_{P}, \delta_{N}$ - forgetting coefficients, which describe probability of consumers moving to the stage of insensitive;

$\propto$ - coefficient which describe probability of consumer to gain interest of particular product category;

$\gamma_{I}$ - coefficient which describe probability of consumer which just have made a purchase to gain an interest in recurring purchase;

$\gamma_{P}-$ coefficient which describes probability of positively impressed consumer to gain an interest in repeating purchase and making another decision;

$\beta_{P}-$ coefficient which describes magnitude of influence of positive recommendations on purchasing decision;

$\beta_{N}-$ coefficient which describes magnitude of influence of negative recommendations on purchasing decision;

$\alpha_{P}-$ coefficient which describes frequency of forming a positive impression of a purchase;

$\alpha_{N}$ - coefficient which describes frequency of forming a negative impression of a purchase.

In order to compare the model with the one proposed in (Li, Yang, Yang, Xiong, Wu, \& Yan Tang, 2018) we will use its coefficients (see Table 2) and analyze system's behavior for different initial values $S_{i}$.

A closed system with 1000 consumers in total is being considered. As shown on Figure 2 - in case of no initial recommenders and no other effects, natural movement among stages results in insensitive consumers becoming sensitive but experiencing no recommendations can't find out about the product hence sales don't happen.

In case of $0,5 \%$ consumers being persuaded by the enterprise itself or a personal experience in benefits of a product or a service, sales surge at the beginning of a planning horizon which can be explained
Table 2

\section{Coefficient values of the model}

\begin{tabular}{|c|c|}
\hline$\propto$ & 0,1 \\
\hline$\beta_{P}$ & 0,01 \\
\hline$\gamma_{I}$ & 0,1 \\
\hline$\delta_{I}$ & 0,45 \\
\hline$\alpha_{P}$ & 0,3 \\
\hline$\alpha_{N}$ & 0,2 \\
\hline$\delta_{P}$ & 0,05 \\
\hline$\delta_{N}$ & 0,85 \\
\hline$\gamma_{P}$ & 0,4 \\
\hline$\beta_{N}$ & 0,02 \\
\hline
\end{tabular}

as an interest due to novelty with a consequent stabilization among all stages.

Equilibrium of a closed system without additional disturbances provides stable sales at the level of 52 units per period (See Figure 3).

In case of $10 \%$ of recommenders at the beginning almost instant peaking is being observed with a consequent stabilization at the same level as in the previous case (see Figure 4).

As a result, it leads to a conclusion that if an enterprise can somehow control a number of initial recommenders it defines only a speed of reaching the equilibrium and more intensive sales at the beginning of the modeling horizon. 


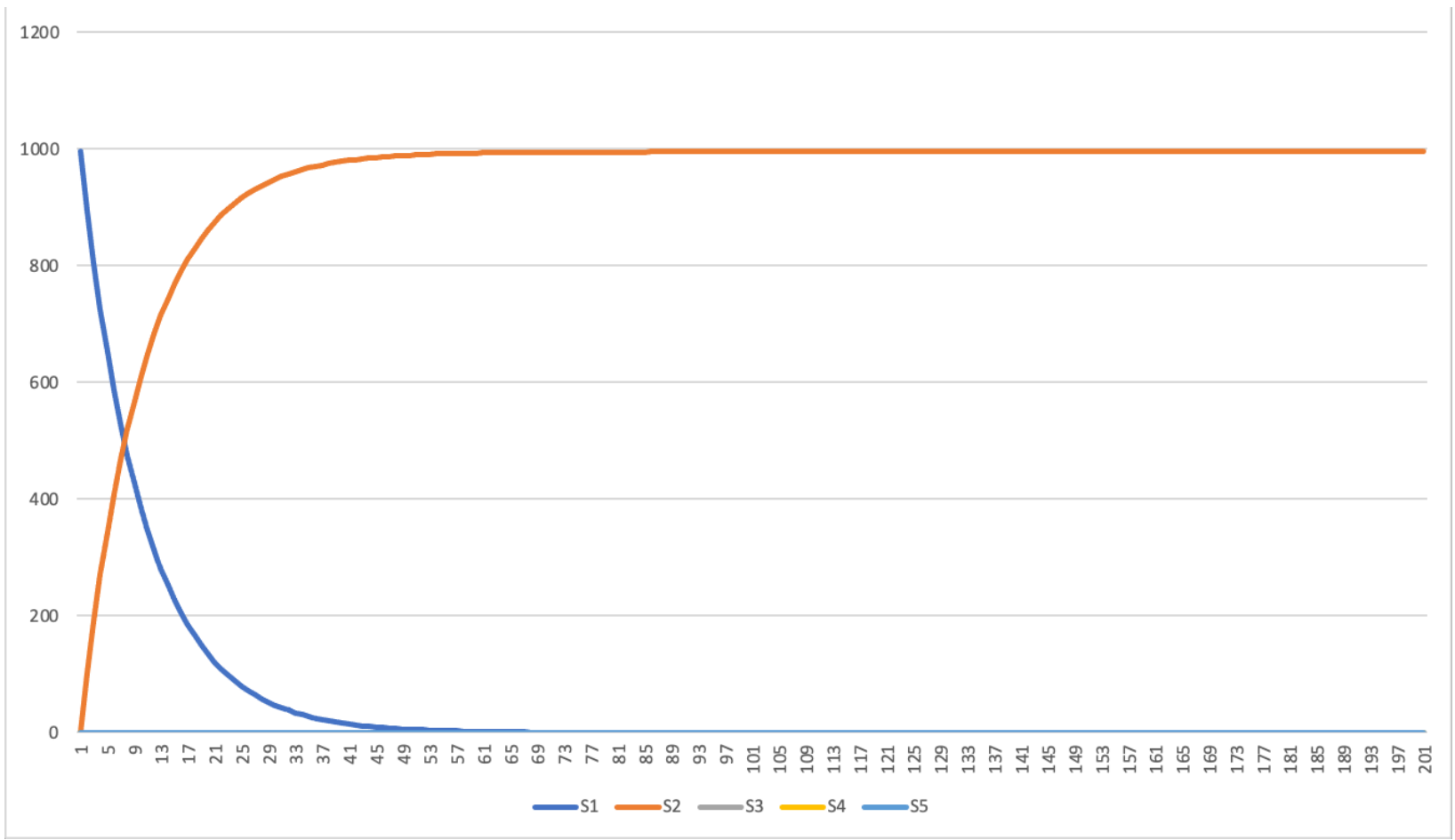

Figure 2. Stage dynamics without initial recommenders

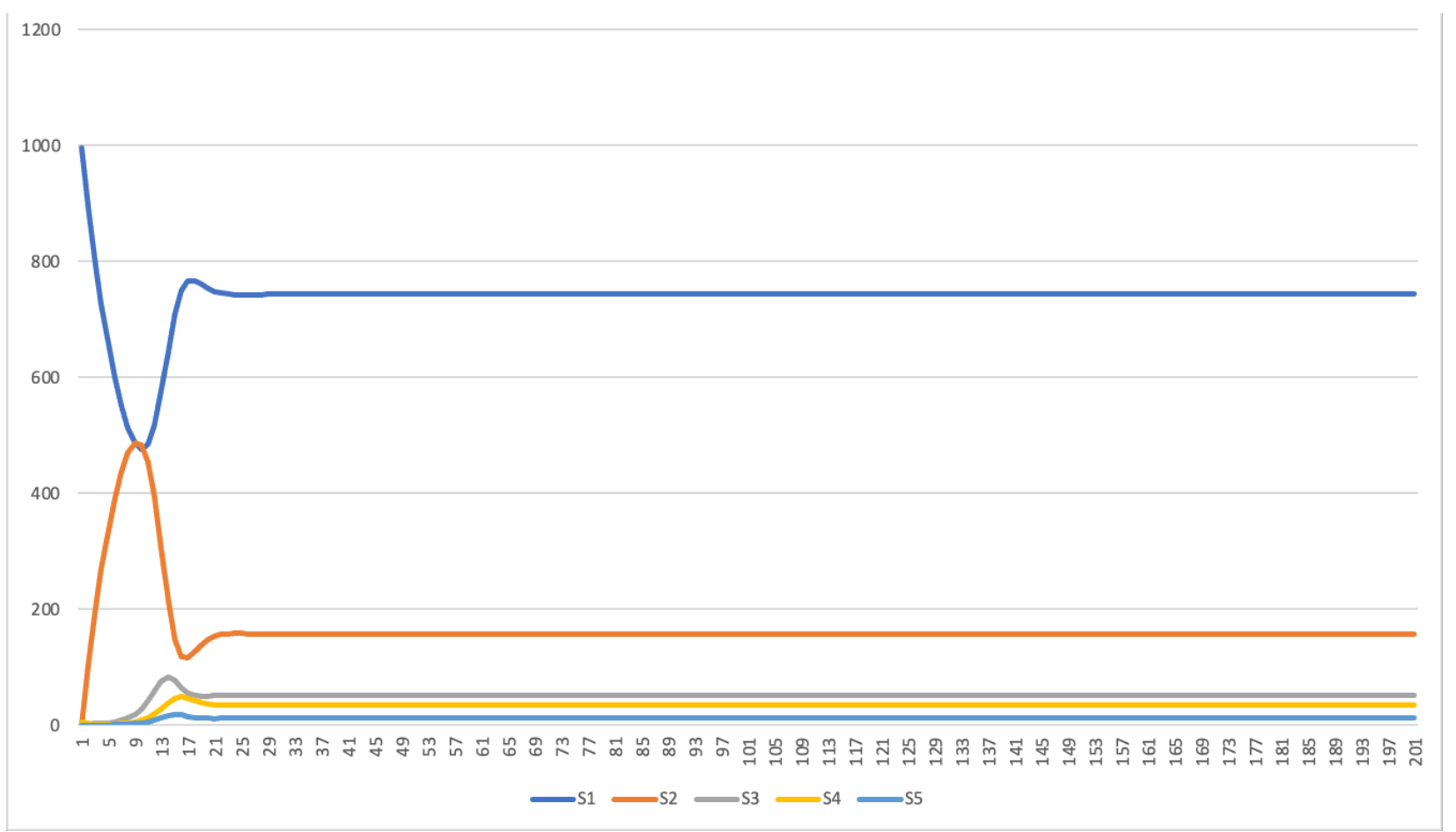

Figure 3. Stage dynamic with 5 initial recommenders

\subsection{Optimization model assembling}

Next step of a framework is turning descriptive model into optimization one, which again will be shown on an example.

Let's consider enterprise's abilities of managing system's dynamic. The model can incorporate control means based on different marketing tools, all of which are based on different influence effects, hence require different approaches for math modeling. There are several marketing tools which utilize WOMM effects (Keller \& Fay, 2016):

1) "seeding" particular ad message by sharing it among close group of impactful peers which can influence their social circles - "influencers"; 
Vol. 2 No. 3, 2021

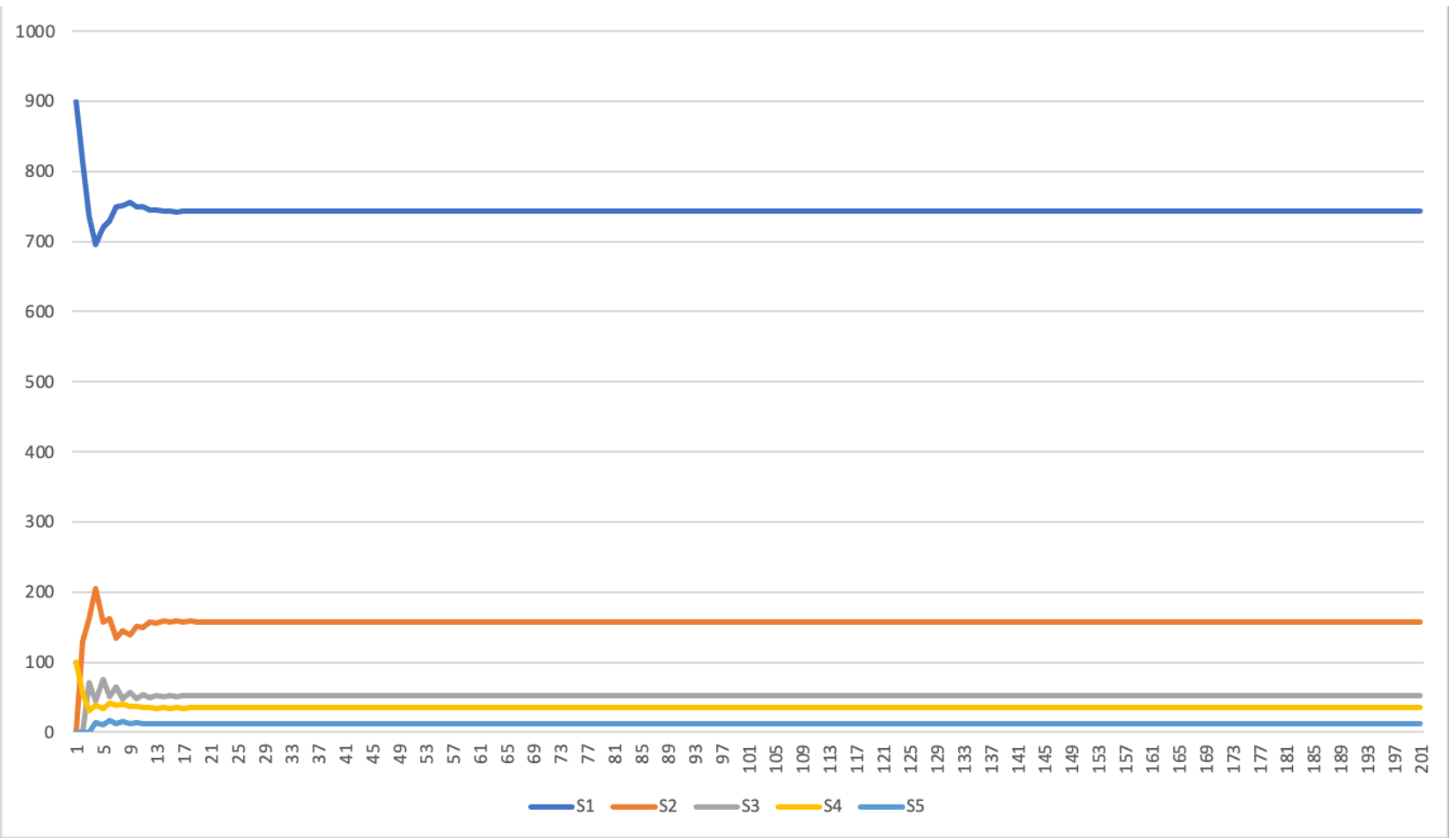

Figure 4. Stage dynamic for 100 initial recommenders

2) encouraging previous customers to refer their friends with some reward for every new customer referred;

3) viral marketing: broadcasting such an ad that majority of consumers would voluntarily tend to share with their peers which would result in a broad advertising reach; usually those messages are masked to be an entertainment with a hidden advertising content;

4) agent campaigns, also known as "network marketing": members of those campaigns function as sales managers and are being rewarded with a percentage of sales done.

Modern tendencies show a lack of trust in traditional ad channels. At the same time, credibility and even desire to replicate influencers' behavior is becoming more common which lays a foundation for WOMM.

Let $S_{6}$ mark a group of influencers. Conceptual scheme is being shown at Figure 5 .

Added links are being explained below:

1. Enterprise provides influencers a product or service with a substantial discount or even for free,

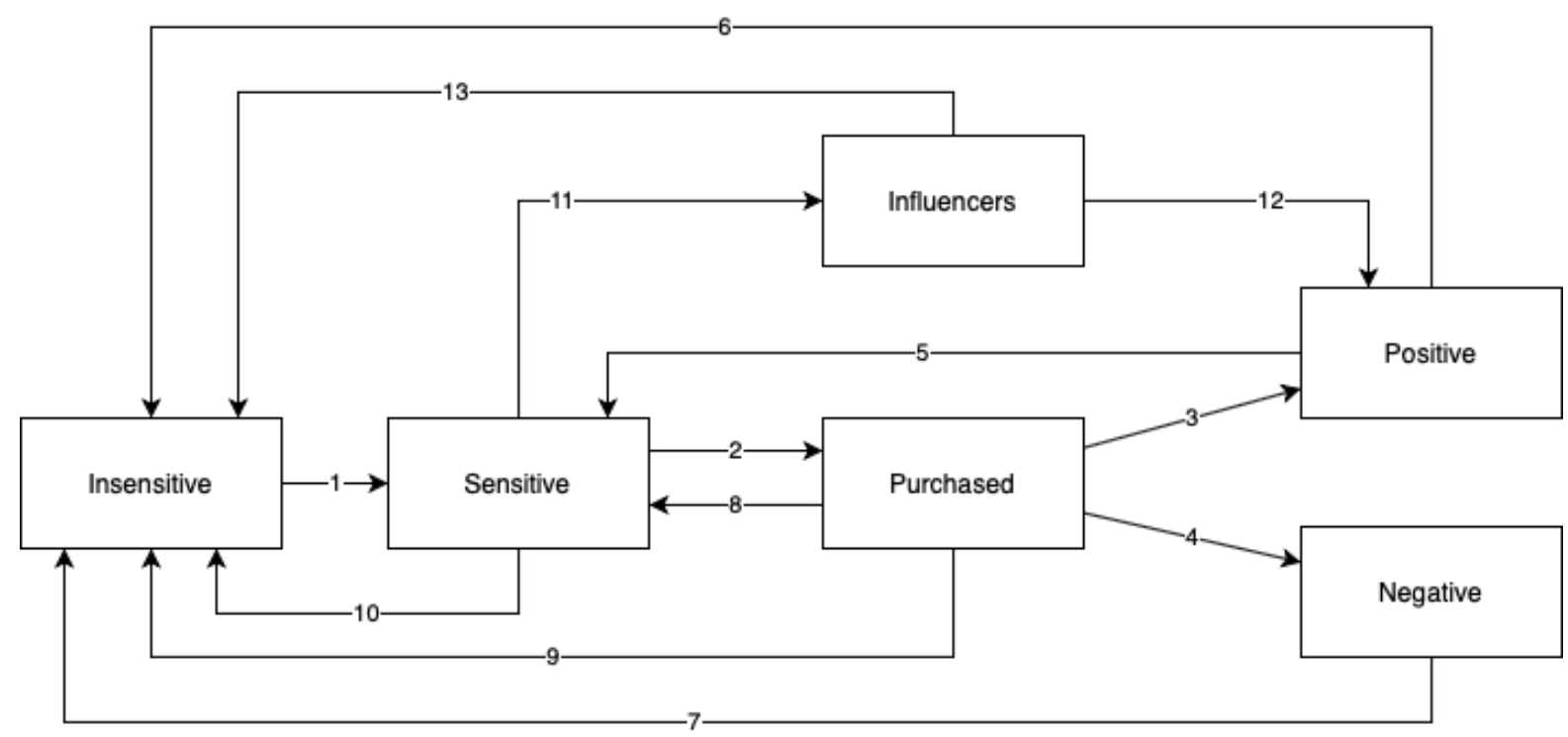

Figure 5. Conceptual scheme of WOMM with control ability 
counting on them to form a positive impression and spread recommendations among their social circles;

2. As a product or service has been a bargain for the influencer, a positive impression is expected to be formed more frequently;
3. Naturally, there's a fraction of influencers which is not impressed, hence loses interest in a product category.

Math definitions for extended model are shown in Table 3.

Extended math model can be written as a set of equations:

$$
\left\{\begin{array}{c}
S_{1}(t+1)=S_{1}(t)+\beta_{N} S_{5}(t) S_{2}(t)+\delta_{I} S_{3}(t)+\delta_{P} S_{4}(t)+\delta_{N} S_{5}(t)+\delta_{F} S_{6}(t)-\mu S_{1}(t) \\
S_{2}(t+1)=S_{2}(t)+\mu S_{1}(t)+\gamma_{I} S_{3}(t)+\gamma_{P} S_{4}(t)-\beta_{N} S_{5}(t)-\beta_{P} S_{4}(t)-x(t) \\
S_{3}(t+1)=S_{3}(t)+\beta_{P} S_{4}(t) S_{2}(t)-\delta_{I} S_{3}(t)-\gamma_{I} S_{3}(t)-\alpha_{P} S_{3}(t)-\alpha_{N} S_{3}(t) \\
S_{4}(t+1)=S_{4}(t)+\alpha_{P} S_{3}(t)+\alpha_{F} S_{6}(t)-\delta_{P} S_{4}(t)-\gamma_{P} S_{4}(t) \\
S_{5}(t+1)=S_{5}(t)+\alpha_{N} S_{3}(t)-\delta_{N} S_{5}(t) \\
S_{6}(t+1)=S_{6}(t)+x(t)-\delta_{F} S_{6}(t)-\alpha_{F} S_{6}(t)
\end{array}\right.
$$

Table 3

Definitions of extended model

\begin{tabular}{|c|c|c|c|c|c|c|}
\hline & $S_{1}$ & $S_{2}$ & $S_{3}$ & $S_{4}$ & $S_{5}$ & $S_{6}$ \\
\hline$S_{1}$ & & $\propto S_{1}$ & $?$ & - & - & \\
\hline$S_{2}$ & $\beta_{N} S_{5}$ & & $\beta_{P} S_{4}$ & - & - & $x_{t}$ \\
\hline$S_{3}$ & $\delta_{I} S_{3}$ & $\gamma_{I} S_{3}$ & & $\alpha_{P} S_{3}$ & $\alpha_{N} S_{3}$ & \\
\hline$S_{4}$ & $\delta_{P} S_{4}$ & $\gamma_{P} S_{4}$ & $?$ & & - & \\
\hline$S_{5}$ & $\delta_{N} S_{5}$ & $?$ & $?$ & - & & \\
\hline$S_{6}$ & $\delta_{F} S_{6}$ & - & - & $\alpha_{F} S_{6}$ & - & \\
\hline
\end{tabular}

$\delta_{F}-$ coefficient of forgetting which describes a probability of influencers losing interest in a product category;

$\alpha_{F}$ - coefficient which describes a frequency of an influencer forming a positive impression from a product or a service;

$x$ - amount of influencers which have been embraced by an enterprise in a period $t$.

Let's make an assumption that an enterprise provides a product to influencers for free. Then, profits of such advertising campaign can be calculated as following:

$$
\begin{aligned}
& P=\left(\sum_{t=1}^{T} S_{3 t}-\sum_{t=1}^{T} S_{6 t}\right) p \\
& S_{1}(t+1)=S_{1}(t)+\beta_{N} S_{5}(t) S_{2}(t)+\delta_{I} S_{3}(t)+\delta_{P} S_{4}(t)+\delta_{N} S_{5}(t)+\delta_{F} S_{6}(t)-\mu S_{1}(t) \\
& S_{2}(t+1)=S_{2}(t)+\mu S_{1}(t)+\gamma_{I} S_{3}(t)+\gamma_{P} S_{4}(t)-\beta_{N} S_{5}(t)-\left(\beta_{P} S_{4}(t)+\beta_{F} S_{6}(t)\right) S_{2}(t)-x(t) \\
& S_{3}(t+1)=S_{3}(t)+\left(\beta_{P} S_{4}(t)+\beta_{F} S_{6}(t)\right) S_{2}(t)-\delta_{I} S_{3}(t)-\gamma_{I} S_{3}(t)-\alpha_{P} S_{3}(t)-\alpha_{N} S_{3}(t) \\
& S_{4}(t+1)=S_{4}(t)+\alpha_{P} S_{3}(t)+\alpha_{F} S_{6}(t)-\delta_{P} S_{4}(t)-\gamma_{P} S_{4}(t) \\
& S_{5}(t+1)=S_{5}(t)+\alpha_{N} S_{3}(t)-\delta_{N} S_{5}(t) \\
& S_{6}(t+1)=S_{6}(t)+x(t)-\delta_{F} S_{6}(t)-\alpha_{F} S_{6}(t)
\end{aligned}
$$

In general, $\beta_{F} \beta_{P}$, but based on assumption above, an equality makes sense:

$$
\beta_{F}=2 \beta_{P}
$$

For the practical implementation, the last equation should be validated or estimated based on a completed advertising campaign of an enterprise which utilized 
Vol. 2 No. 3, 2021

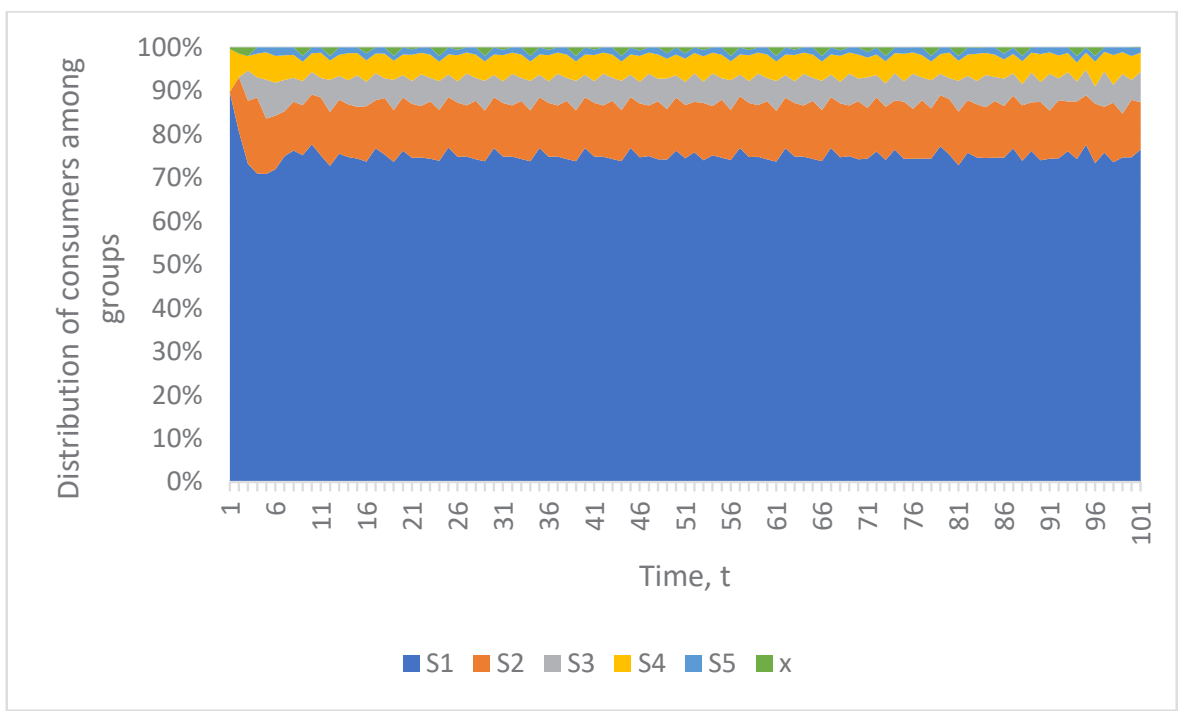

Figure 6. Stage dynamics of a controlled system

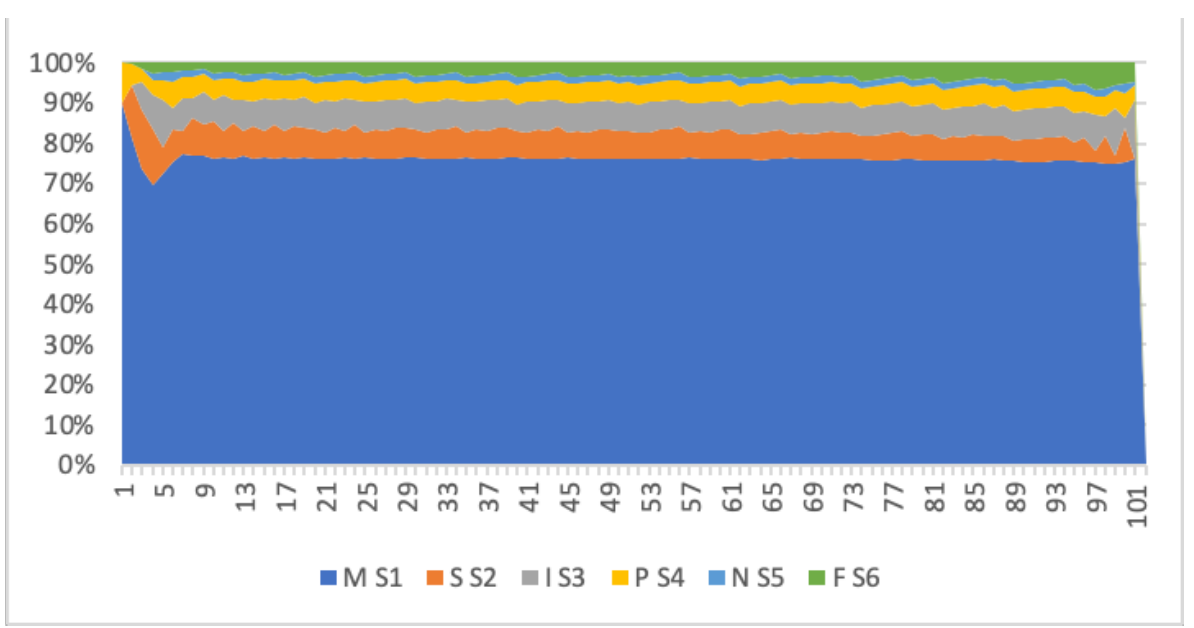

Figure 7. Stage dynamics in case of amplified influencers' impact

WOMM tools and could be described with a conceptual model proposed in the article. Methodically, it is recommended for advertisers to evaluate two metrics: a number of customers which made a purchase after seeing a peer recommendation and a number of those who made a purchase after perceiving influencer's content. Both numbers can be easily obtained by utilizing commonly known promo-code technique which supposes that a customer can obtain a unique code from either a peer recommendation or an influencer's message and use the code to receive a discount, which allows the enterprise to tie each purchase to a particular source of influence.

For the same market of 1000 consumers, no more than $2 \%$ of influencers, and $10 \%$ of initial positively impressed consumers expected profits would be 6903,46 which is $32,5 \%$ than it would be expected if counting only on natural factors of cross-stage movement with no WOMM intervention of an enterprise. Stage dynamics for the case is shown on Figure 7.

While WOMM is being a useful tool of persuasion in making a purchase, traditional mass advertising is still a suitable tool for building awareness, which is known to be a foundation of a marketing. (Chan, Leung, Tan, \& Tse, 2015). Considering that, it makes sense to show such a model modification that would allow taking into account traditional advertising tools as well. It can be shown as a controlled movement from $S_{1}$ to $S_{2}$. It is known that marginal effect of advertising expansion approaches zero once $100 \%$ awareness has been achieved в (Ostrianyn, Dynamic budgeting of an advertising campaign, 2017); incorporation of an advertising saturation effect into a generalized marketing model is shown below:

$$
S_{2}(t+1)=S_{2}(t)+\mu S_{1}(t)+\gamma_{I} S_{3}(t)+\gamma_{P} S_{4}(t)-\beta_{N} S_{5}(t)-\left(\beta_{P} S_{4}(t)+\beta_{F} S_{6}(t)\right) S_{2}(t)-x(t)
$$


$\mu=1-1 / e^{\xi g(t)}$

$\xi$ - coefficient of diminishing returns on scale.

$g(t)$ - budget allocations on traditional advertising channels

In (13) a coefficient describing probability of natural interest in budget category $\propto$ is being defined as dependent on $g(t)$. It is obvious from (13), that for $g(t) \rightarrow \infty$ it is expected $\mu \rightarrow 1$.

\section{Conclusion}

An example realization of a generalized enterprise marketing model was proposed for modelling an advertising campaign utilizing WOMM tools. Abilities of a proposed model to describe existing model as well as tuning them from simple descriptive to more advanced and useful for a practical use at the enterprise - optimization ones, has been illustrated. A capability of a model to account means of marketing control based on different tools utilizing different effect and, consequently, math approaches, has been shown. An expected profits of a baseline descriptive model has been compared against advanced models describing utilization of influencers as a WOMM tool for two different assumptions: the one of equal peer and influencer impact and the one of more powerful influence of the latter.

\section{References:}

Li, P., Yang, X., Yang, L.-X., Xiong, Q. Wu, Y., \& Yan Tang, Y. (2018). The modeling and analysis of the wordof-mouth marketing. Physica A, 493, 1-16.

Guruge, M. (2018). Comparison between Attributes related to Celebrity Endorsement and Social Media Influencer Marketing: A Conceptual Review. Sri Lanka Journal of Marketing, 4(1), 17-37.

Silverman, G. (2001). The Secrets of Word-of-Mouth Marketing: How to Trigger Exponential Sales Through Runaway Word of Mouth. New York: AMACOM.

Kozinets, R., de Valck, K., Wojnicki, A., \& Wilner, S. (2010). Networked Narratives: Understanding Wordof- Mouth Marketing in Online Communities. Journal of Marketing, 74 (March, 2010), 71-89.

Keller, E., \& Fay, B. (2016). How to use influencers to drive a word-of-mouth strategy. London: Warc Best Practice.

Chan, T., Leung, F., Tan, P., \& Tse, D. (2015). Role of conventional ads in a digital age: effects of internet and conventional advertising on brand awareness and brand desire in China. International Journal of Electronic Commerce Studies, 6(1), 87-98.

Ostrianyn, S. (2017). Dynamic budgeting of an advertising campaign. BUSINESS-INFORM, 10, $204-209$.

Ostrianyn, S., \& Yakovenko, O. (2020). Generalized model of the enterprise marketing activity management. Scientific notes of Ostroh Academy National University, «Economics series, 17(45), 128-135.

Sukma Wijaya, B. (2012). The Development of Hierarchy of Effects Model in Advertising. International Research Journal of Business Studies, 5(1), 73-85.

Ahmed, Q. \& Mustafa Raziq, M. (2017). The Social Media Advertising Model (SMAM): A Theoretical Framework. Journal of Managerial Sciences, 11(3), 117-144.

Naumovska, L., \& Blazeska, D. (2016). Public relation based model of integrated marketing communications. UTMS Journal of Economics, 7(2), 175-186.

Key, T., \& Czaplewski, A. (2017). Upstream social marketing strategy: An integrated marketing communications approach. Business Horizons, 60(3), 325-333.

Finne, A., \& Grönroos, C. (2017). Communication-in-use: customer-integrated marketing communication. European Journal of Marketing, 51(3), 445-463.

Ostrianyn, S., \& Yakovenko, O. (2020). Modeling of advertising activity in conditions of uncontrolled demand factors. In Theory and practice of management of business entities, pp. 353-359. Dnipro: Bila K. O.

Yakovenko, O. (2017). Math models of activity processes in economic dynamics. Dnipro: Bila K.O. 